\title{
Pragmática ecofánica del contradiscurso artístico 'oportunista' en política
}

\section{(Echophanic pragmatics of the 'opportunist' artistic counter-discourse in politics)}

MANUEl Balsera Fernández Grupo de Investigación HUM-887 ("Traductologia, Discurso y Cognición")

Fecha de recepción: 5 de septiembre de 2013

Fecha de aceptación: 30 de septiembre de 2013

Resumen: En este artículo nos proponemos estudiar, basándonos en la teoría de la Relevancia (D. Sperber y D.Wilson, 1995, 2004; Carston, 2002), algunos aspectos pragmáticos y traductológicos (E.A.Gutt, 1991, 1998, 2004) del contradiscurso político-electoral sobre Barack Obama fundamentado en obras de arte. El lenguaje pictórico-visual con toda la complejidad de sus estructuras y procesos, posee un enorme potencial comunicativo pero necesita del anclaje verbal, especialmente en los textos multimodales de naturaleza ecoica, si éstos tienen fines persuasivos. Centraremos nuestra atención en dos obras pictóricas consideradas canónicas del arte y de la cultura estadounidense: Washington Crossing the Delaware de Emanuel Leutze (1851) y American Gothic de Grant Wood (1930).

Palabras clave: Pragmática, Relevancia, Barack Obama, Multimodalidad, Ecoicidad en arte, Contrapublicidad,

Abstract: The aim of this article is to examine within the framework of cognitive pragmatic theory (D.Sperber and D.Wilson, 1994, 2005; Carston 2002), some pragmatic and translational aspects of art (E.A.Gutt, 1991; 1998; 2004). As applied to a political-electoral counter-discourse about Barack Obama with strong artistic connections. The visual-pictorial language has a great communicative potential in spite of its complex structures and processes, it really wants to have verbal anchorage in order to achieve persuasive purposes, especially in multimodal texts of echoic nature. We shall be focusing here on two artworks considered by many critics canonical 
pictorial icons of American culture: Washington Crossing the Delaware by Emanuel Leutze (1851) and American Gothic by Grant Wood (1930).

Key words: Pragmatics, Relevance, Barack Obama, Multimodality, Echoicity in art, Counterdiscourse.

\section{INTRODUCCIÓN}

La obra de arte, entendido este último como 'campo de estímulos diversos', se presta, en multitud de ocasiones, a ser reconvertida, por mor de su ambigüedad consustancial, en réplicas o knockoffs producidas por 'receptores activos' que con sus propias interpretaciones crean una serie insólita de meta-representaciones polarizadas como una 'plástica cotidiana de la disensión política'. Esto ocurre, especialmente en publicidad, al considerarse que las imágenes son mucho más cercanas a la realidad que la palabra confiriendo a la obra de arte y a sus réplicas una intencionalidad comunicativa potente lograda a través de: (a) la maestría del autor al expresarse y, (b) la habilidad interpretativa meta-representacional del receptor basada en una serie de parámetros locativo-temporales, de conocimiento personal y de contexto cultural no-universal. Cuando no se dispone de un código global y muy preciso, la comunicación va a desarrollarse casi exclusivamente sobre la faceta cognitiva inferencial. La ausencia de código (bien es sabido que el significado de la imagen no es universal) hace más complicada la comunicación, pero no la imposibilita porque basta añadir alguna mutación y/o algún elemento escrito para que se cargue de nueva intencionalidad comunicativa. A veces, se pueden producir sobreinterpretaciones cognitivas no semejantes del modelo raíz como 'descodificaciones aberrantes' ${ }^{1}$ generando lo que nosotros hemos llamado 'ecoicidad disidente o no afín'2.

Desde nuestra perspectiva interlingüística e intercultural de traductores -es decir, intérpretes de una comunicación secundaria- y desde la posición heurística de que la traducción tiene mucho que ver con la cognición y con la comunicación -hecho que no ha sido considerado por estimarlo escasamente pertinente (o simplemente porque no se han

\footnotetext{
${ }^{1}$ Umberto Eco en su obra La estructura Ausente. Introducción a la semiótica incluye en la pág.212, un esquema sobre la descodificación aberrante en las comunicaciones de masas a cuyo pie puede leerse: "En este modelo, cuando el destinatario no resuelve la ambigüedad de mensaje o no sabe realizar los actos de fidelidad necesarios para hallar los códigos de emitente (por deficiencias de conocimiento o por la presencia de circunstancias desviatorias), pasa a referirse a códigos privados e introduce connotaciones aleatorias"

Balsera Fernández, M., "Ecoicidad y paratraducción meta-representacional del info-universo cognitivo-visual generado por el logotipo de Barack Obama" (en prensa).
} 
atrevido a abordarlo) por parte de muchos teóricos de corte lingüísticoestructuralista (funcionalista en su mayoría) hasta tiempos bien recientes-, consideramos que cualquier elemento plástico de una cultura está en constante proceso de creación y renegociación por parte de sus interpretantes, quienes con sus aportaciones 'culturales' lo irán enriqueciendo continuamente mediante un proceso que nosotros hemos denominado "ecoicidad" o producción de nuevos ecos comunicativos epidemiológicos (Sperber, 1996) de una matriz original.

Estas representaciones mentales individuales, no necesariamente sincrónicas, pasarán al mundo de lo público mediante procesos virales ${ }^{3}$, especialmente, en los nuevos medios electrónicos interactivos de comunicación, capaces de facilitar el acceso a la 'información' de multitud de receptores. Estas representaciones culturales son representaciones que pueden replicarse a sí mismas y en muchas ocasiones "mutan" iniciando, en determinadas circunstancias, una nueva serie comunicativa.

La conformación de estas meta-representaciones se hará por 'semejanza interpretativa' con las piezas artísticas originales generando variantes pragmáticas icónico-verbales "ad hoc" que serán aplicadas, en nuestro caso, a la figura política de Barack Obama como crítica satírica y/o contrapublicitaria, mediante distorsiones calculadas, presentadas bajo la forma de comunicación multimodal persuasiva ${ }^{4}$. En multitud de casos, tal comunicación es encubierta ("covert" es el término empleado por Wilson y Gutt) y también por Tanaka (1994) porque en ella se hace un uso emotivo de las referencias y un uso referencial de las emociones para la obtención de mayores efectos contextuales. Si bien la relevancia es un principio computacional mediante el que se ahorra tiempo y energía, en publicidad, sin embargo, la obtención de mayores efectos contextuales suele

\footnotetext{
${ }^{3}$ Término empleado por Dan Sperber en su Explaining Culture, para significar que la cultura es un hecho epidemiológico de carácter cognitivo entre las representaciones mentales de los individuos (la mayoría de las cuales no se transmiten nunca) cuando afirma: "representations are transformed almost every time they are transmited, and remain stable only in certain limiting cases. A cultural representation in particular is made up of many versions, mental and public one. Each mental version results from the interpretation of a public representation which is itself an expression of a mental representation" (1996: 25-26). Esta visión constituye una postura anti semiótica puesto que describe el proceso comunicativo como intercambio de mensajes mientras que la semiótica describe los procesos comunicativos en términos de producción de sentido y está centrada en el signo.

${ }^{4}$ La persuasión es uno de los signos más distintivos de la publicidad. Su objetivo es cambiar conductas, sentimientos, intenciones y puntos de vista por ello se recurre a estrategias comunicativas precisas como la cooperación a nivel cognitivo y la comunicación encubierta (covert communication), es decir, tratando de involucrar al destinatario de forma consciente en la recuperación de un significado que no es evidente recurriendo para ello al método de la utilización de categorías retóricas como mejor medio de expresión.
} 
compensar el mayor esfuerzo de procesamiento exigido al receptor mediante la activación de implicaturas débiles o muy débiles ${ }^{5}$. Todas ellas han sido obtenidas en un contexto que debe entenderse inmerso en una situación comunicativa concreta, de coyuntura intencional del mensaje implicado, con facetas de naturaleza más o menos efímera (significado ocasional) en la que se hace necesario incorporar factores psicológicos, sociales, antropológicos y culturales de 'oportunidad' política. La intención persuasiva está basada en tres pilares: (a) el de la razón, mediante el cual se apela al conocimiento y se trata de 'convencer'; (b) el de la emoción, a través del cual se apela a los sentimientos y,(c) el de la seducción, que consiste en apelar directamente a los instintos.

Para este fin centraremos nuestra atención en dos obras pictóricas consideradas canónicas del arte y de la cultura estadounidense: Washington Crossing the Delaware de Emanuel Leutze (de 1851) y American Gothic de Grant Wood (de 1930). Su conversión paulatina en iconos populares ha sido posible merced a la fosilización interpretativa de algunos de sus hipotéticos mensajes a los que Pierce llamaba 'abducción' inferencial que han llegado a ser conformados a través del tiempo para la memoria colectiva como una serie de significados que pretenden adquirir la condición de atemporales. Sin embargo, ahora se asoman al presente merced a nuevos usos intencionados más o menos efímeros y circunstanciales (ecofanías) como afirma Umberto Eco en su obra Apocalípticos e Integrados (1965) es frecuente en la praxis comunicativa el uso de algo 'muy conocido' para significar una gran variedad de cosas ${ }^{6}$. Una respuesta plausible a la pregunta: ¿por qué resultan tan atractivos los anuncios que se sirven del arte? podría, básicamente, resumirse en que lo estético impregna culturalmente nuestro sentido del gusto y se convierte en

\footnotetext{
${ }^{5}$ Es necesario recordar que la teoría de la Relevancia aúna el proceso semiótico y el inferencial. El primero se produce en la fase de la interpretación en la que se está descodificando una señal. En un proceso semiótico la asociación entre estímulo experimentado y el no experimentado parece más refleja e inevitable, el proceso inferencial tiene lugar cuando sobre la base de los inputs descodificados y otros datos contextuales, el receptor alcanza informaciones conclusivas no codificadas. La actividad inferencial es deductiva y no es refleja como la semiótica.

${ }^{66}$ Umberto Eco es uno de los primeros autores que de una manera sistemática se ocupó de discurso publicitario en La estructura ausente (1968) enfocándolo desde el punto de vista de la semiología y como profesor de comunicación visual también se preocupó del arte: La definición de arte (1970); Historia de la belleza (2004); Historia de lo feo (2007). Sperber y Wilson contemplan más bien un marco de estudio orientado al uso que se hace de los símbolos considerándolos desde su perspectiva relevantista: la descodificación es insuficiente en la interpretación de los estímulos por lo que ha de combinarse con la inferencia, entendiendo esta última como un proceso falible de formación y evaluación de hipótesis.
} 
un arma de superioridad publicitaria al ser capaz de estimular nuestras emociones con mayor intensidad que otros reclamos.

Abraham A. Moles ${ }^{7}$ definió muy bien el proceso de socialización de lo estético mediante el concepto de lo kitsch. Actualmente, la imagen pluricodificada en comunicación aumenta su presencia en la sociedad. Se afirma que las culturas son fruto del 'lenguaje' de cada comunidad y una gran parte de ese lenguaje tiende a ser hoy día una sutil mezcolanza icónico-verbal merced a los novedosos procesos comunicativos de los nuevos medios interpersonales e interactivos. No debemos olvidar que en nuestra sociedad las imágenes no son inocentes ni carentes de intención pero de las mismas per se sólo se pueden extraer inferencias.

Lo visual es un tema central en muchas ramas de la traducción, no solo en campos como la traducción técnica especializada o la traducción audiovisual sino que también afecta a otras formas icónico-textuales como la publicidad, el arte y el mundo del comic. La forma metodológica de abordar este maremágnum necesita de la aplicación de nuevos conceptos que sirvan para plantear 'nuevos hechos de traducción' como el de la 'ecoicidad' entendida como fenómeno general y el de 'ecofanía' como unidad ecoica meta-representacional con sesgo comunicativo aplicada a representaciones icónicas e icónico-verbales. Se trata de formas que permiten prolongar la visión de la traducción como reescritura efímera con sesgo comunicativo viral. En un artículo anterior tratamos el tema de la ecoicidad y de la paratraducción meta-representacional ${ }^{8}$ y en él planteábamos la necesidad de ampliar el término paratraducción ${ }^{9}$. Como señala E. A. Gutt (1991) no es posible en una situación de comunicación secundaria, exigir que se compartan todas las implicaciones analíticas y contextuales. Este autor avanza el concepto de semejanza interpretativa como el más adecuado a la hora de explicar el proceso, siempre dinámico, de realizar una traducción. La teoría de la Relevancia nos permite dibujar un marco cognitivo explícito que dé cuenta del fenómeno de la traducción como un uso interlingüístico de los inputs como 'semejanza interpretativa'.

\footnotetext{
${ }^{7}$ Moles, Abraham A., El kitsch. El arte de la felicidad. Trad.: Josefina Ludmer. $1^{\mathrm{a}}$ ed. Buenos Aires: Paidós, 1971. (Barcelona, 1990). El término de origen alemán lo definió el autor como la forma de arte que se adapta a las dimensiones del hombre medio y por esta razón el kitsch es el arte de la felicidad. El concepto está en gran medida ligado al postmodernismo (la transgresión es uno de los mayores rasgos de su estética) dado que la función del arte ha cambiado radicalmente en los tiempos modernos. El kitsch a la vez atrae y repele, es acogido al mismo tiempo con ironía y tolerancia. Jean Duvignant pone de manifiesto que una mirada creadora puede rescatar estos subproductos artísticos.

${ }^{8}$ Balsera Fernández, M. (opus citatum)

${ }^{9}$ Creado por Yuste Frías y su equipo de la Universidad de Vigo (cf. Yuste Frías, 2011)
} 


\section{UN PUNTO DE PARTIDA: LA IMAGEN COMO TEXTO}

Si por una parte Zabalbeascoa ${ }^{10}$ (1990: 77-78) defendía que "la traducción es una actividad natural e irreprimible" (...) que "se ha producido en los últimos años una extensión de la aplicación y del uso de la traducción a muchísimas actividades de la vida moderna", Álvarez de Prada ${ }^{11}$ (2003) explícitamente sostiene que el discurso publicitario utiliza de forma oportunista el discurso de los artistas plásticos. De acuerdo con este punto de vista, nosotros pretendemos aquí extenderlo para el análisis del discurso político icónico e icónico-verbal basado en la obra artística. La referida autora toma como punto de partida la consideración de la imagen como texto cuando señala: "la imagen como texto-icónico está avalada por diversos autores" entre los que destaca: (a) las aportaciones de la escuela semiótica de Tartú (Estonia) con Lotman a la cabeza, (b) las de Umberto Eco quien en su obra Lector in fabula (1981:73) afirma: "un texto (...) representa una cadena de artificios expresivos que el destinatario debe actualizar". Este autor, desde una óptica académica, considera a la semiótica como una red interdisciplinaria, por consiguiente no solo muestra interés por el mensaje publicitario en sí mismo sino que hace alusión a la interpretación del "uso de los textos" y (c) la de Santos Zunzunegui para quien "el texto es una secuencia de signos que producen sentido" posición estrictamente vinculada al proceso de semiosis que es reconstructivo y, en consecuencia, basado en la 'estabilidad semiótica' del signo por contraposición a la perspectiva relevantista más centrada en la mente de los receptores y, por ende, en la 'variabilidad de los signos'. Según el semiótico americano Charles Morris, la semántica — que estudia el significado libre de contexto- hace abstracción de los usuarios.

A modo de resumen, conviene resaltar que desde esta perspectiva la consideración de las imágenes como textos goza de gran consenso general. Entre los estudiosos de la imagen destaca el semiótico del arte Omar Calabrese quien defiende que la imagen artística, en general, y la imagen publicitaria en particular, deben ser conceptuadas como textos. Afirma

\footnotetext{
10 Zabalbeascoa Terran, P., "Aplicaciones de la traducción a la enseñanza de las lenguas extranjeras" (1990), en el que afirma: "La palabra clave que hace que converjan todos estos estudios en un esfuerzo común es la palabra "comunicación": todo está en función de lograr una mayor efectividad de la comunicación. Todo ha de comunicar algo, desde las manifestaciones artísticas hasta el diseño industrial".

${ }^{11}$ Alvarez de Prada, Gloria, Didáctica del discurso icónico-verbal: las artes plásticas como pretexto publicitario. Tesis doctoral. Universidad de Córdoba, 2003. La autora ha desarrollado posteriormente otros trabajos como: "El diálogo entre arte y publicidad: un enfoque multidisciplinario", en EDUCO, Revista de investigación educativa. Servicio de Publicaciones de la Universidad de Córdoba, 2004.
} 
también que el arte es una forma de comunicación ${ }^{12}$ diferente: mientras que la ciencia comunica mediante afirmaciones, el arte, sin embargo, presenta valores pero no puede discutirlos. Como ya señalamos anteriormente, es frecuente en la praxis comunicativa el uso de algo 'muy conocido' para significar una gran variedad de cosas lo decía Eco en su obra Apocalipticos e Integrados en la que, además, afirmaba que la comunicación de masas está formada por una gran cantidad de significaciones inusuales. Por otra parte, la teoría de la Relevancia es un marco de estudio "orientado al uso" y el objetivo de su enfoque en comunicación es identificar los principios que subyacen en las elecciones (falibles) del oyente. Las empresas se benefician, con renovada frecuencia, de este subterfugio publicitario y, también lo hacen, marcas de dulces o de tarjetas de crédito. El artista brasileño Vik Muñiz utiliza materiales como el chocolate, la mermelada, el hilo, la tinta, el polvo, el alambre o los juguetes en sustitución de la pintura, y luego fotografía el resultado. Muñiz recurre a iconos de la historia del arte como La Gioconda, vueltos invisibles a fuerza de ser masivamente reproducidos, y trata de restituir al acto de mirar la sensación de placer y de provocación. Debemos señalar, además, que una de las características del arte posmodernista es el tratamiento irónico e irreverente de las obras canónicas.

Las aportaciones de Barthes en su obra La muerte del autor (1995) y las de Culler en Literary Theory (2000) cambian el foco desde donde surge la interpretación: el texto mismo y el lector, antes que la vida del autor. Nosotros queremos trasladar esta visión también al arte. Desde nuestro posicionamiento reinterpretamos a Culler adaptando a nuestra visión algunas de sus características específicas del texto: (a) el arte trae a primer plano lo estético, es decir, logra transmitir o generar un efecto determinado en el lector y lo obliga a relacionar forma y contenido (b) el texto artístico termina valiéndose por sí mismo, es independiente de las intenciones y la voluntad del autor, (c) la obra artística está compuesta enteramente de ficción y no de realidad, aunque es necesario reconocer que existe un contexto en el cual ha sido creada, (d) cada obra contiene, a su vez, guiños a miles de obras anteriores, así como reflexiones sobre el quehacer artístico y sus implicaciones. Para Barthes un texto está constituido por un espacio de múltiples dimensiones en el que concuerdan y contrastan diversas

\footnotetext{
${ }^{12}$ Desde la valoración de la obra de arte como texto de interlocución y evento comunicativo, es necesario reconocer, como aclara Garroni, que ante todo ésta obedece a un sistema de relaciones metaoperativas, en las cuales los lenguajes artísticos contribuyen a la proposición de operaciones y los estilos configuran índices o características de representación, con valencias semióticas deducibles desde las posibilidades de que la obra adquiere en e momento en que entra en contacto con el espectador, extendiendo su capacidad de simbolizar.
} 
escrituras, ninguna de las cuales es la original. Para este autor "el texto es un tejido de citas provenientes de los mil focos de la cultura" (Barthes, 1995: 67) y nosotros agregamos que una variante muy importante de la cita son los ecos de ahí nuestro intento de hablar de 'ecoicidad' y de 'pragmática ecofánica' entendida esta última como el uso intencional de las manifestaciones ecoicas (ecofanías). Sperber y Wilson conciben la mención de una manera amplia, desde la cita propiamente dicha al eco. Jorgensen, Miller y Sperber (1984), en su teoría de la "mención ecoica" sostienen que la interpretación de lo irónico se produce porque el hablante le señala al oyente hechos, comentarios, opiniones, expectativas o normas previamente conocidas por ambos; sin embargo, al propio tiempo, evita informar acerca de esas realidades, solo se las menciona, indicando claramente su actitud hacia las mismas.

Desde una vertiente comunicativa queremos señalar que los modelos a base de la función codificadora no están preparados para describir la 'indeterminación comunicativa' como el de Claude E. Shannon. El posterior modelo de Schramm siguiendo al de Lasswell y al de Shannon contribuye con nuevas aportaciones. Por ejemplo, el feedback ${ }^{13}$ y la noción de campo de experiencia como aquella memoria común que hace posible una comunicación efectiva (la ausencia de esta memoria era una de las principales críticas al modelo de Shannon) no obstante para estos modelos, el proceso de producción de la información sigue siendo una caja negra. Multitud de trabajos posteriores han demostrado que el modelo de código semiótico es insuficiente porque describe (cómo) pero no explica (el por qué) de la comunicación; no aclara, entre otras cosas, el papel de gran responsabilidad que tiene el receptor en la activación de inferencias. Distintos autores han puesto de manifiesto la ineficacia de dicho modelo al aplicarse estrictamente a la comunicación humana.

En la terminología propia de la teoría de relevancia, cualquier estímulo externo o representación interna que sirva como input de un proceso cognitivo podrá considerarse relevante para un sujeto en una ocasión determinada. Pero ¿cuándo un input es relevante? Cualquier input (una percepción visual, un sonido, un enunciado, un recuerdo) es relevante para un sujeto cuando entra en contacto con una información previa de la que éste dispone, produciendo con ello una serie de resultados que le

\footnotetext{
${ }^{13}$ Yus Ramos en su libro la Interpretación y la imagen de masas (1997: 51) Sugiere "una idea más ecléctica de la comunicación de ficción, dando tanto al autor, como al texto y sobre todo al lector como posibles fuentes de significado que no siempre coinciden". Existen una multiplicidad de formas de practicar el feedback: la reiteración, la respuesta empática, la formulación de algún tipo de pregunta, manifestando acuerdo/desacuerdo, mediante la continuidad y la acción ecofánica intencionada.
} 
incumben (Deirdre Wilson y Dan Sperber, 2004: 239). La pragmática cognitiva puede llegar a investigar de una forma efectiva la intencionalidad y los efectos que producen los diferentes discursos mediáticos sobre los destinatarios, por lo que creemos que la pragmática cognitiva es particularmente válida para complementar los estudios semióticos de estos discursos (dado que los estudios semióticos sobre los atributos de cada código comunicativo se convierten en "semiótica de x") a la hora de desvelar, por ejemplo, la finalidad persuasiva de la publicidad, la ideología latente en el texto de la prensa escrita y su relación con las fotografías que lo acompañan, o la conjunción de la imagen y el texto en los cómics. (Yus Ramos, 2001).

Señalaba Alberto Manguel ${ }^{14}$ (2001: 286) que "el miedo nos hace olvidar que, en un sentido muy esencial, todo texto es "interactivo"; que cambia según el lector, la hora y el lugar en que se lo lee. Cada lectura particular lleva al lector a la "espiral de la interpretación", como la ha llamado el historiador francés Jean-Marie Paillier. Es imposible evitarla; toda lectura añade un giro a su vertiginosa ascensión. La "lectura pura" no ha existido nunca". Sperber y Wilson (1986) se decantan en su análisis por la inferencia no demostrativa, es decir, aquella en la que la verdad de las premisas solo hace que la verdad de las conclusiones sea probable por contraposición a la inferencia demostrativa que se produce cuando la verdad de las premisas garantiza la verdad de las conclusiones.

La relevancia es una teoría cognitiva de la interpretación que defiende que en la comunicación humana intervienen procesos mucho más complicados que los de codificación/descodificación. El cognitivismo intenta anclar los procesos de interpretación en entidades que existen antes de que la interpretación se realice. El cognitivismo en arte consiste en una postura que establece que una obra artística es valiosa en la medida en que contribuye al conocimiento. Guijarro Morales $^{15}$ (2005: 25) afirma: "las ciencias cognitivas han establecido de manera rotunda que los seres

\footnotetext{
${ }^{14}$ Alberto Manguel, En el bosque del espejo. Ensayos sobre las palabras y el mundo. Madrid: Alianza, 2001. Con anterioridad, afirmaba el mismo autor en su artículo: "De San Agustín a la computadora" (cf. http://edant.clarin.com/suplementos/cultura/1999/05/30/e-00401d.htm) lo siguiente: "Cuando leo un texto en una página o una pantalla, lo leo en silencio. A través de un proceso o una serie de procesos increíblemente complejos, montones de neuronas en sectores específicos de mi cerebro descifran el texto que absorben mis ojos y lo hacen comprensible para mí, sin necesidad de emitir las palabras en beneficio de mis oídos. Esta lectura silenciosa no es una ocupación tan antigua como creemos (...) Cada lectura prolonga otra, iniciada alguna tarde hace miles de años y de la cual no sabemos nada; cada lectura proyecta su sombra en la página siguiente, dándole contenido y contexto".

${ }_{15} \mathrm{~J}$, L, Guijarro Morales, "Encuadre del fenómeno del arte en el nuevo paradigma científico del cognitivismo", en: Cuadernos del Minotauro, nº.2, 2005, pp. 17-48.
} 
humanos son capaces, no sólo de almacenar representaciones en su mente; pueden, además y con pasmosa facilidad, almacenar representaciones incrustadas en otras representaciones (...) hasta el punto no sólo de recordar, sino de prever cosas que pueden acontecer en el futuro", es decir, los individuos no son receptores pasivos, sino que son capaces mediante una lectura 'activa' (mediante sus conocimientos previos y la realimentación) de generar nuevas expectativas. El receptor puede, por tanto, y esto es lo esencial, activar implicaciones que nunca fueron pensadas por el emisor. Para este autor el origen del arte y lo que lo caracteriza es que se trata de una actitud humana. Esta noción de "actitud" aparece en Sperber y Wilson (1986/1995) como una manera de procesar la información del mundo que nos rodea en relación con nuestra capacidad incrustadora de representaciones. Según Sperber y Wilson, los efectos poéticos son implicaturas débiles, casi siempre, cargadas de emoción. Sobre éstos ha incidido, desde un punto de vista cognitivo, A. Pilkington (2000). Nosotros queremos añadir a esta visión una nueva dimensión del problema digna de estudio: la ocasionada por el lector o receptor-activo capaz de producir mediante meta-representaciones particularizadas nuevos mensajes ex novo como reescrituras ampliadoras o distorsionadoras del contenido original de mensaje (ecofanías). Las metarrepresentaciones constituyen el enlace entre el lenguaje [o cualquier otro input] y la mente. Nuestros pensamientos son representaciones mentales, y los seres humanos necesitan representar en su mente las representaciones mentales de los demás (López Folgado, 2010). Es decir, nuestra mente ha evolucionado para hacerse las representaciones de las representaciones de otros. Es esta capacidad de meta-representación la que nos ayuda a interpretar las intenciones del emisor del mensaje aunque este tome derroteros divergentes del emisor primigenio e incluso aunque haya transcurrido una inmensidad de tiempo (décadas y centurias) siempre que la nueva producción tenga un carácter cronético (oportunidad del mensaje en el tiempo) y posea un sesgo comunicativo intencional ligado a ese momento preciso locativo-temporal, de conocimiento personal del receptor y de contexto cultural no universal.

2. UN PUNTO DE LLEGADA: EL CONTRADISCURSO OPORTUNISTA EN LAS OBRAS DE REFERENCIA

\subsection{Obama en el papel de George Washington}

El oportunismo publicitario en política es aquella actitud que aprovecha no sólo los recursos gráficos y artísticos sino también las circunstancias momentáneas de un hecho de interés o de una noticia 
relevante para usarlas en su propio beneficio (ingroup) o, como en el estudio de caso que nos ocupa, para hacer sátira o crítica del oponente (outgroup) y para ese fin usa como soporte para sus sarcasmos, ironías y reproches una obra de arte: Washington crossing the Delaware (1891) de Emanuel Leutze.

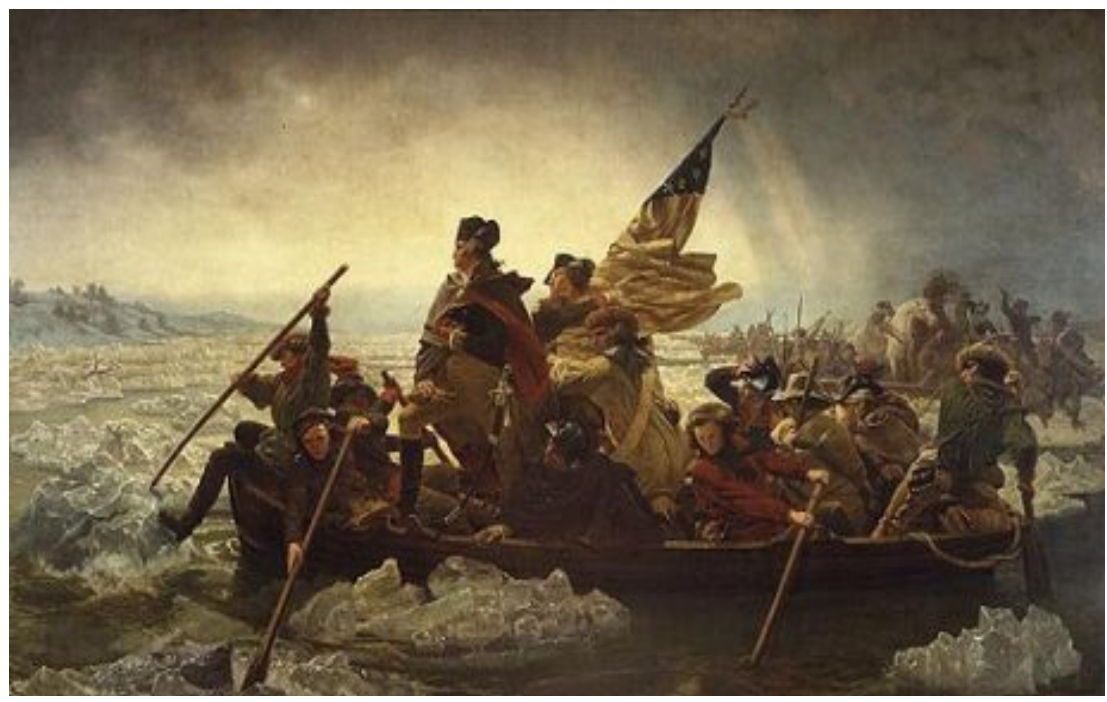

Se trata de un cuadro monumental que se exhibe en el Metropolitan Museum of Art de Nueva York y representa un episodio de gran importancia emotiva más que militar: Washington y sus hombres cruzando el río Delaware en la noche de Navidad de 1776, unos meses después de la declaración de independencia de las trece colonias en Filadelfia, tratando de realizar un ataque por sorpresa desde la rivera de Pensilvania a la de Nueva Jersey, en una operación logística difícil y peligrosa, que tenía como objetivo las fuerzas mercenarias alemanas (Hessian army) y a una fracción del ejército británico que se encontraban en la orilla opuesta, cerca de la localidad de Trenton (New Jersey). El ataque por sorpresa no sólo detuvo el avance británico, sino que confirmó el liderazgo de Washington. Lo que ocurrió aquel día (batalla de Trenton) tuvo unos efectos para la moral y el espíritu de la Revolución estadounidense tan increíbles que el cruce del río pasó a considerarse como uno de los aspectos clave de la independencia de las Colonias americanas, un punto de inflexión decisivo. Gracias a las reproducciones en grabado, tan populares en el siglo XIX, se difundió la fama del cuadro. Hoy en día esta pintura forma parte de la historia de 
Estados Unidos, por lo que significó y por lo que significa en la actualidad (sus conexiones históricas, literarias y artísticas) y es estudiada en los colegios donde, en la mayoría de las aulas, se cuelgan sus reproducciones. Se ha convertido en un icono de la cultura popular con repercusiones en objetos comerciales cotidianos.

\subsection{Una breve descripción}

Una mirada rápida y superficial al cuadro, que imita en su estilo a las obras de otros pintores románticos como Delacroix (la libertad guiando al pueblo) o Géricault (la balsa de la Medusa), nos hace centrar nuestra mirada en la barca que encabeza la acción y focaliza, casi de manera instantánea, nuestra atención en la figura de Washington (clincher icónico) que se yergue, en su centro, imperturbable transmitiendo quietud y altivez al mismo tiempo (ethos retórico). Mientras, doce soldados, más uno que no podemos ver pero cuya presencia se intuye por el cañón de su arma saliendo de entre el amasijo de cuerpos situados a la derecha luchan por controlar y hacer avanzar el bote en las alborotadas y frías aguas salpicadas de bloques de hielo que obstruyen su marcha. Un líder y trece hombres, uno por cada una de las 13 colonias americanas. Se puede deducir, por medio de una inferencia fuerte (es decir, muy probable), que se trata de tropas estadounidenses por la bandera con barras y estrellas que sostiene uno de ellos. ${ }^{16}$ La variedad de sus ropajes (sombreros y camisas) nos induce a una inferencia débil, es decir poco probable: su posible pertenencia a diferentes regiones coloniales. Arriba, a la izquierda, en el cielo, una estrella solitaria y luminosa marca el camino a seguir hacia la tierra distante que simboliza la consecución de un primer objetivo en la lucha por el logro de la libertad, como una señal de victoria en la batalla de Trenton. Comprobamos que mientras que el lado izquierdo del cuadro es luminoso, simbolizando el futuro que ha de venir, el lado derecho es más oscuro y tormentoso, como si se tratara de un reflejo del período pasado, gris y negro, que se acaba de abandonar (pathos retórico). El cruce del río puede interpretarse como una transición emotiva desde un pasado desastroso y poco ilusionante que se abandona hacia un futuro alentador por el que es necesario luchar y sufrir intensamente.

\footnotetext{
${ }^{16} \mathrm{El}$ autor se permite una licencia histórica al incluir en él una bandera que no fue adoptada con carácter oficial por Congreso Continental hasta el 14 de Junio de 1877. Se dice que Leutze era un entusiasta abolicionista razón por la que incluyó en el cuadro a un afroamericano (el tercer tripulante contando desde la proa).
} 


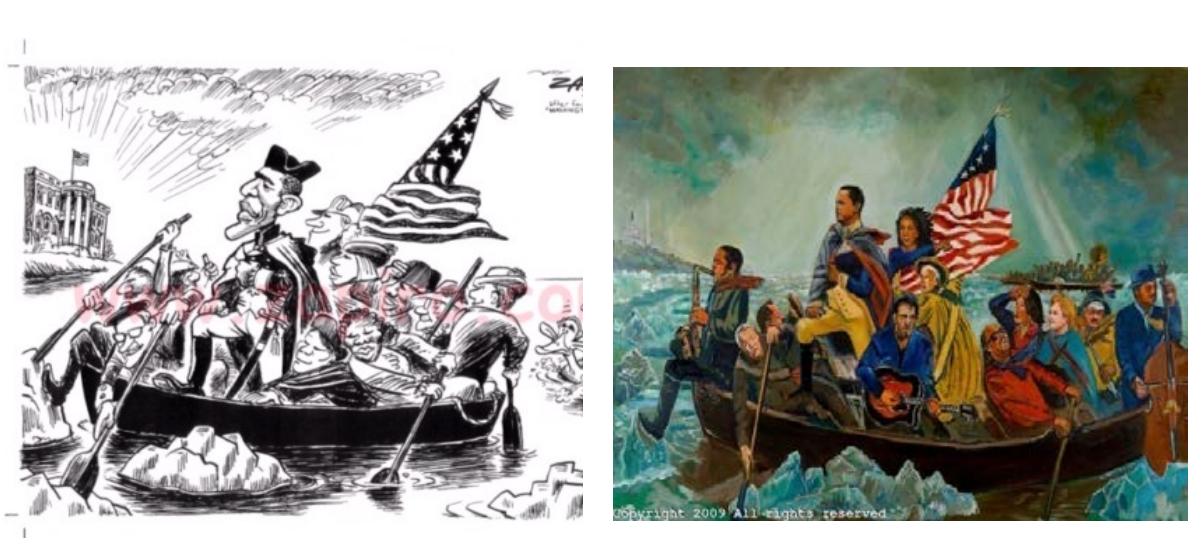

Ecofanía $n^{\circ}$. 1a: Viñeta publicada en el Sun Times el 1 de noviembre de 2008. Obra del humorista gráfico sudafricano Jonathan Shapiro conocido internacionalmente como Zapiro. Se trata de una crítica mordaz al proyecto propugnado por Obama de redactar un plan de reforma migratoria que permitiera la legalización de millones de indocumentados. Antes de las elecciones Obama anticipó que si los latinos le votaban en masa, enviarían una clara señal a los políticos de que el asunto necesitaba abordarse, y que esto haría reflexionar a los republicanos en su oposición al tema. La sátira consiste en mostrar un marco o framing negativo de ese programa sobre política migratoria presentando a Obama como George Washington en la barca del cuadro pero en esta ocasión los que le acompañan son inmigrantes. Obama está introduciendo en el país a personas indocumentadas de todas las nacionalidades que muestran su alegría al divisar en el horizonte la Casa Blanca como el hito que, de ser conseguido, les permitiría un futuro esperanzador para convertirse en ciudadanos estadounidenses y adquirir así una nueva vida. Sin embargo, Obama deja detrás de sí ahogándose en las turbulentas y frías aguas, a los verdaderos ciudadanos estadounidenses representados por las figuras de John McCain, de Sarah Palin y de George W. Bush.

Ecofanía $n^{\circ}$. 2a: la pintura "Obama Crossing" fue realizada por el pintor figurativo y artista afroamericano Wayne Manns (2009) con el fin de celebrar la elección de Barack Obama como el primer presidente negro en la historia de EE.UU. Como ya indicamos anteriormente, el posmodernismo se caracteriza por el tratamiento irónico e irreverente de las obras canónicas. La tripulación que acompaña a Obama, a bordo de una barca que lleva inscrito el nombre de "Hope" en su proa, representando el papel de Washington, son celebridades y figuras muy conocidas para los 
estadounidenses: Oprah Winfrey (afroamericana y millonaria estrella de televisión considerada una de las personas más influyentes de EE.UU., que apoyó de forma rotunda a Obama en su campaña electoral); Bruce Springsteen (legendario cantante apodado el 'Boss' que organizó conciertos en apoyo a la campaña de Obama); Stevie Wonder (cantante de leyenda de la famosa firma discográfica Motown que también se declaró fan de Obama); Hillary Clinton (rival político para la nominación dentro del partido y nombrada por Obama ministra de asuntos exteriores); Michelle Obama (su esposa, sosteniendo la bandera); Colin Powell (general afroamericano de cuatro estrellas jubilado y antiguo ministro de Asuntos Exteriores que declaró que él había votado por Obama); David Axelrod (uno de los más importantes asesores en la campaña presidencial de Obama); Jesse Jackson (símbolo durante décadas de la defensa de los derechos civiles en EE.UU., y candidato a las primarias en dos ocasiones en el partido demócrata); Joe Biden (vicepresidente en el gobierno de Barack Obama) y sujetando el timón (helm) de la nave; John Coltrane ( músico de jazz y saxofonista), cuya obra está conscientemente vinculada a la lucha por los derechos civiles de los negros. De este cuadro se realizaron reproducciones, en una edición limitada, para celebrar este histórico momento de la historia norteamericana.

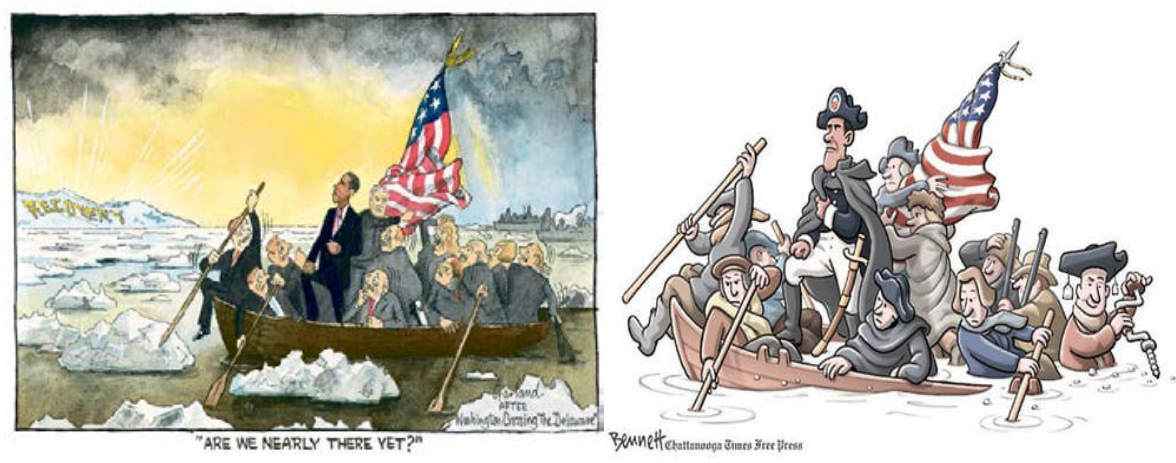

Ecofanía $n^{\circ}$. 3a: Nicholas Garland publica "Are we nearly there yet?" el 19 de marzo de 2009 en el Daily Telegraph. Obama y su gabinete tratan de cruzar el río con el fin de alcanzar el anhelado objetivo que se vislumbra resplandeciente al final del viaje. En la otra orilla brilla, con grandes letras sobre el horizonte, la palabra recovery (recuperación económica) la barca parece navegar sin rumbo incapaz de avanzar en la dirección correcta en contraposición a "yet Washington knew where he was going". Barack 
Obama, conocedor de que la economía norteamericana estaba en su peor momento desde la Gran Depresión de los años 30 la abordó en su programa como un asunto que requería la máxima prioridad. Cuando asumió el cargo la crisis, iniciada en 2007, exigía modificar drásticamente las políticas del pasado reciente. El centro de la estrategia del presidente era favorecer a la clase media. Pero al llegar a la presidencia de EE.UU., se vio obligado a modificar sustancialmente los tres pilares de los que hablaba en su programa: (a) es cierto que se aprobó el plan de recuperación y reinversión ${ }^{17}$ que pretendía crear y salvar entre tres y cuatro millones de puestos de trabajo pero esto fue insuficiente (b) el plan de rescate de las entidades financieras con el fin de reactivar el crédito tuvo un mayor peso. En lugar de prestar más atención a los estímulos macroeconómicos, con una política mucho más intervencionista, que posiblemente hubiera dinamizado la economía como hizo en su día su antecesor Roosevelt con su New Deal (nuevo trato); (c) su tercer pilar iba a consistir en un programa de ayuda para frenar la catarata de impagos y desahucios en el mercado inmobiliario. Su reforma de la salud -destinada a mejorar el ineficiente sistema de seguro privado- pronto se tornó muy impopular desde el punto de vista político. Para los progresistas estadounidenses este fracaso de las promesas electorales se convirtió en un foco de profunda frustración porque significaba haber perdido una oportunidad única para la realización de cambios trascendentales. La obstrucción política republicana fue grande desde los primeros momentos pero arreció con el recién nacido Tea party (2009) movimiento mucho más conservador obsesionado por la política fiscal, la reducción de impuestos y por el recorte drástico del gobierno federal. Estos obstáculos han creado auténticos atolladeros para la salida de las profundidades por la dificultad de aprobar techos de endeudamiento público o la aprobación del presupuesto federal. Es necesario recordar la derrota parcial de Obama (2010) en las midterm elections (elecciones de mitad de mandato) perdiendo su mayoría en el Congreso desde entonces, esta situación se ha enconado gravemente tras la reelección de Obama en 2012., Ilegando al terrible momento actual de provocar un "cierre del gobierno" (goverment shutdown) que podría llevar a EE.UU., a la suspensión de pagos.

Ecofanía $n^{\circ}$. 4a: Sin leyenda o subtítulo (No Caption). Realizada para el Chattanooga Times Free Press por Clay Bennett dibujante de historietas y tiras cómicas políticas ganador del premio Pulitzer de viñetas editoriales

17 Una de las novedades del plan de Obama era la transparencia en la utilización de los 787.000 millones de dólares aprobados en el mismo. Por ello aseguró que todos los ciudadanos podrían tener acceso a la información de los gastos que se hacían a través de la página web www.recovery.gov. 
en 2002. Publicada el 5 de Julio del 2012. Si en 2008 Obama se rodeó de carteles en sus mítines de campaña con la palabra "Hope" (esperanza) cuatro años más tarde la campaña presidencial de Barack Obama para la reelección en 2012 tuvo como eslogan principal la palabra "Forward" (adelante), que equivale a decirle a los estadounidenses que una parte del camino ya ha sido recorrido pero es necesario seguir avanzando porque aún nos queda mucha travesía por hacer. La marca forward permite incluir de nuevo la letra "O" en el horizonte del antiguo logo de la campaña del 2008. Ahí radica el eje principal de la sátira de Bennett pues mientras la tripulación se afana en hacer avanzar la barca (forward) en la parte de atrás de la misma hay un hombre (inferencia fuerte) reconocido por su sombrero del que penden o cuelgan bolsas de té que permiten identificarlo como un 'teabagger' -miembro del partido del té o Tea Party el cuál se afana con un antiguo taladro o barreno en producir una importante vía de agua para hacer que la barca comience a hundirse y no pueda alcanzar la orilla como objetivo final.

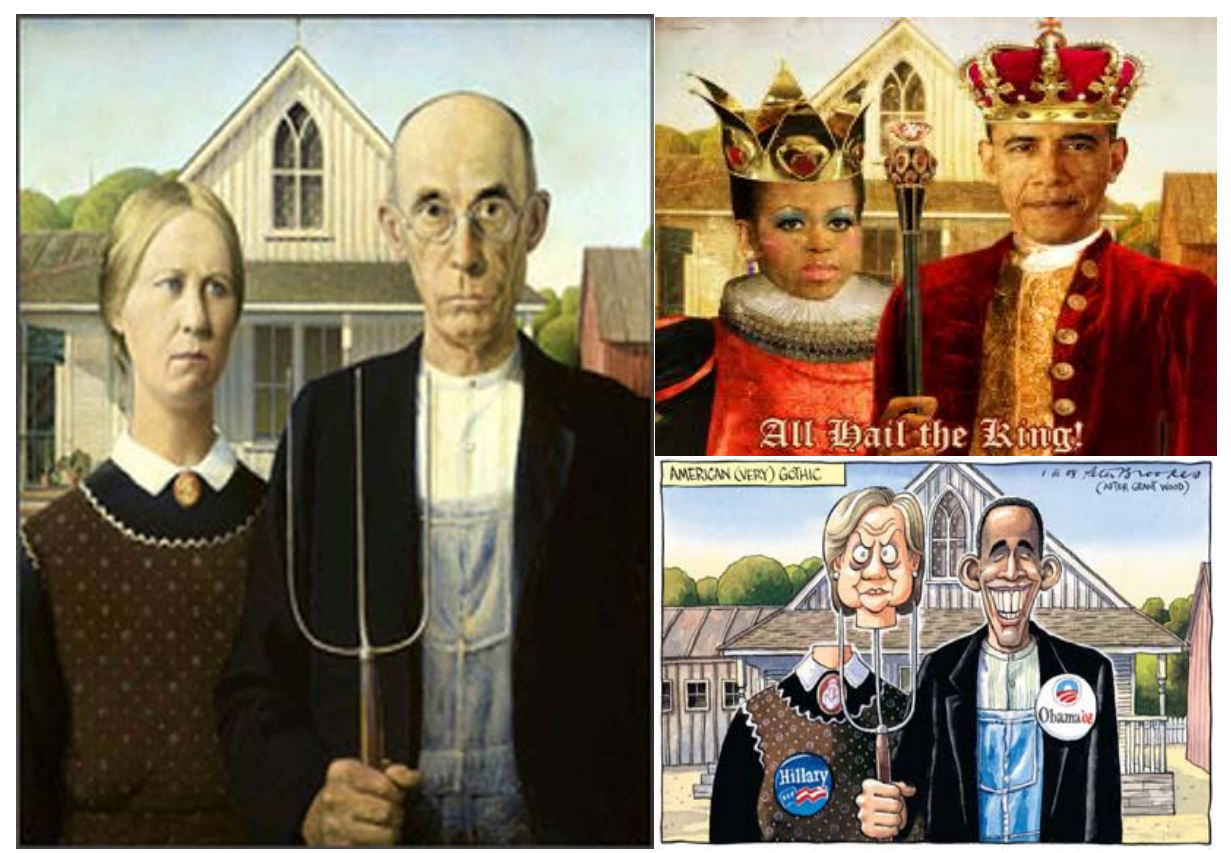

Obama representando uno de los roles de American Gothic 


\section{UNA BREVE PRESENTACIÓN DE LA MATRIZ ARTÍSTICA ECOFÁNICA}

El cuadro titulado (American Gothic [house]) hace referencia a la casa de madera en estilo gótico rural estadounidense con su famosa ventana superior ojival o apuntada y con su mullion o parteluz (Gothic Revival style), de donde el autor tomó su inspiración. Es conocida como casa Dibble fue construida en torno a 1880 y se encuentra ubicada en Eldon (lowa). El autor de la obra es Grant Wood -pintor nacido en el Estado de lowa en 1831 y encuadrado por los críticos de su país dentro de la escuela regionalista, un estilo que triunfó en la década de 1930. A pesar de haber perfeccionado su formación en Europa y recibir influencias clásicas y de la "nueva objetividad" alemana, que rechazaba el expresionismo, se convirtió en un gran defensor del regionalismo en las artes, dando conferencias en su país sobre el tema. La obra está expuesta en el Instituto de Arte de Chicago y pertenece a la colección del mismo. Su hermana Nan Wood Graham y su dentista el doctor Byron McKeeby fueron los modelos de los que se sirvió para ilustrar a esta famosa pareja de granjeros del medio oeste (Midwest) ${ }^{18}$. Wood provoca ambigüedad desde el nivel más básico de interpretación, el de las relaciones de la pareja: ¿esposos, padre e hija? La imagen puede ser usada para comentar una gran variedad de temas como la familia, el puritanismo, el trabajo ético, el individualismo, la propiedad, los rasgos del hombre y de la mujer común, los roles que cada uno de ellos representa o todos al mismo tiempo en una conjunción holística.

Lo cierto es que las figuras representadas se definen de algún modo ante el espectador como tradicionales por sus ropas del siglo XIX o por su mirada y esto constituye una serie de actos comunicativos no verbales. Pongamos como ejemplo la importancia de la mirada de requerimiento intimidatorio en el hombre y huidiza en la mujer creando un lazo de comunicación directa y simbólica, que reafirma su presencia, al solicitar casi de inmediato una reacción del espectador. Según comenta Wanda M. Corn $^{19}$ en su libro The birth of a national icon la intencionalidad primaria de

\footnotetext{
${ }^{18}$ El apelativo de medio-oeste (Mid-West) tiene su origen en que en el siglo XIX estos territorios se encontraban situados entre los estados del este y el lejano oeste o Far-West. Se trata realmente del corazón de EE.UU. (Heartland), una región peculiar caracterizada por las tierras abiertas (openland), la cultura de la granja (farm cultura) y por la existencia de pequeñas localidades (little towns). Existe abundante literatura que destaca la excepcionalidad de esta zona con descripciones vívidas de su ruralismo como epicentro agrícola del país (America fertile crescent) que también destaca los rasgos idiosincráticos de sus habitantes como apunta en su obra Praerie Folks (1892) Halim Garland: brutos y duros paletos (dura vida, duros dialectos, trabajo monótono un tanto deprimente y desalentador) que han sido objeto de parodia (lampoon) en multitud de ocasiones.

${ }_{19}$ The Birth of a National Icon: Grant Wood's "American Gothic". Wanda M. Corn and Grant Wood. Art Institute of Chicago Museum Studies Vol. 10, The Art Institute of Chicago Centennial
} 
Wood era una sátira del ámbito vital del granjero pero, con el devenir del tiempo, la obra se ha convertido en un icono que viene a representar los valores familiares de la América profunda: White anglo-saxon protestant (WASP). En ella están contenidas todas aquellas expresiones culturales que transmiten sin palabras la pertenencia a un colectivo y a la manera como se relacionan sus integrantes.

\section{LAS RÉPLICAS ECOFÁNICAS}

La ecofanía $n^{\circ}$. 1b: "Todos saludan al rey" (All hail the King!). Viene a incidir en un mito fascinante y recurrente para todas las generaciones occidentales (especialmente aquellas más íntimamente conectadas con la cultura británica), el mito de Camelot con Arturo y sus caballeros que ha sido amplificado hasta la saciedad por el cine. Su mensaje básico 'fosilizado' es que la historia preserva a quienes propugnan y defienden lo bueno, lo justo y lo bello. Lo que equivale a decir que gobernar es perseguir el bien común, reemplazar la violencia por el diálogo, y promover los valores de la civilización. En EE.UU., el mito adquirió una nueva dimensión para designar una 'nueva cultura democrática' que se instaura allí a partir de la elección como presidente $\mathrm{n}^{\circ}$. 35 del joven senador demócrata John Fitzgerald Kennedy tras casi medio siglo de hegemonía del partido republicano. A este hecho hay que añadir la figura de su esposa y primera dama, Jacqueline, como la nueva Ginebra y las de sus hijos conformando 'otra' familia modelo como la del cuadro pero en este caso de confesión católica. JFK contaba con el apoyo de un equipo de personas, entre las que se encontraba su hermano Robert, que recuerda la poética de la Tabla redonda y la conectan con el programa de política interna del presidente llamado la nueva frontera (New Frontier). Pero todo ello acaba en tragedia con la fatídica desaparición de J.F. Kennedy (1963) en el magnicidio de Dallas (Texas), con el asesinato de su hermano Robert Kennedy (1968) en Los Ángeles (California) y, también, con la muerte del líder del movimiento racial, galardonado con el premio Nobel, Martin Luther King asesinado en Memphis (Tennessee) en el mismo año. Esta cadena de acontecimientos luctuosos pone fin a esta etapa de política ilusionada y da paso a una serie de liderazgos no siempre dotados de la misma dimensión motivadora. Una nueva 'reviviscencia' del mito se produce transcurrida más de media centuria, cuando a comienzos de 2008 Ted Kennedy, en contra del aparato del partido demócrata, apoya al senador negro por Illinois Barack Obama como su candidato a la presidencia de EE.UU., proclamando que desde la

Lectures (1983), pp. 252-275. Published by: The Art Institute of Chicago. Article Stable URL: http://www.jstor.org/stable/4104340 
muerte de su hermano no había sentido la misma emoción. Recapitulemos sobre algunas interesantes similitudes entre ellos: Obama, al igual que JFK en su época, se ha distinguido por su talento extraordinario para la oratoria, ambos acompañados por sus respectivas "reinas Ginebras" (Jacqueline y Michelle), por tener el mismo número de hijos e incluso por tener animales domésticos en la casa Blanca. Ambos presidentes han sabido presentar a los ciudadanos una imagen de familia moderna estadounidense comprometida con su época. Cada una de estas familias 'modelo' ha sido capaz de solventar con energía los tiempos de enorme dificultad que les tocó vivir como la construcción del muro de Berlín o el problema de los misiles en Cuba (JFK) o las guerras de Afganistán, Irak, la tortura, la crisis económica y otros muchos acontecimientos de máxima actualidad (Obama) pero desde una óptica positiva ajena a la crítica mordaz. Al mismo tiempo, ambas han sido capaces de inspirar a sus generaciones respectivas con la 'poética de la esperanza', con las promesas, cumplidas o no, y las realizaciones de sus programas de gobierno. Por ese motivo el contenido del mensaje contrapublicitario es diáfano, admonitivo y clarificador de la intencionalidad subyacente mediante una fina ironía que enlaza con lo sucedido a JFK. No debemos olvidar nunca la tragedia final de Camelot (la muerte de Arturo), el dramático desmoronamiento de la Tabla Redonda y el caos que pueden originar estas políticas no exentas de utopía que pueden convertir al país en una tierra sin ley y sin rey.

La ecofanía $n^{\circ}$. 2b: American (very) Gothic representa el final de la pugna encarnizada que durante cinco meses sostuvieron los dos candidatos demócratas (identificados políticamente por sus respectivos logos de campaña en forma de pines adheridos en sus ropas) para conseguir la nominación por su partido a la presidencia. Durante la contienda, se planteó una doble dicotomía: mujer/hombre y color de la piel. La primera candidata blanca/el primer candidato negro por lo que los conceptos emocionales 'roles' y 'raza' dividieron a la familia demócrata. Este proceso de primarias interno consiguió movilizar a casi 38 millones de personas en más de 50 Estados. Hillary Clinton logró 18 millones de votos, un récord histórico, pero no obtuvo los delegados suficientes para ganar a Obama, el primer candidato negro de un gran partido con aspiraciones reales de llegar a la Casa Blanca. Aunque Hillary Clinton partía como favorita y defendía que ella era la que contaba con mayor apoyo popular, la batalla fue reñidísima hasta el último momento. El senador por Illinois obtuvo 1627 delegados de los 3253 elegidos que habrían de nominar al candidato en la convención del Partido Demócrata celebrada en Denver (Colorado).

Durante todo el proceso y hasta los albores de la convención una lacerante división imperó dentro del partido hasta que, como desenlace, 
Obama obtuvo la victoria al conseguir el apoyo de los superdelegados - cargos electos del partido y de personas notables que tienen libertad para decidir a quienes apoyan. Esta es la razón por la que en la viñeta Obama presenta triunfalmente con una enorme y terrorífica sonrisa la cabeza de Hillary Clinton clavada en su horca o bieldo metálico de tres puntas como si se tratara de una escena de una película de terror, por esa razón se enfatiza el hecho con el anclaje verbal (very) gothic para establecer un juego de palabras (pun) y relacionarlo simultáneamente con la obra de Grant Wood -de ahí la referencia al pintor en la zona superior derecha-y con la denominada narrativa fílmica gótica o de terror en la que tiene mucha importancia el escenario arquitectónico, dentro del cual los personajes están sujetos a pasiones y emociones desenfrenadas que provocan el final trágico, en este caso, de la familia demócrata. Tras este resultado fue necesario hacer una llamada angustiosa y contundente para conseguir la unidad del partido demócrata con la finalidad de apoyar sin fisuras al candidato electo en su lucha final contra McCain, su rival republicano, para la consecución de la presidencia estadounidense.

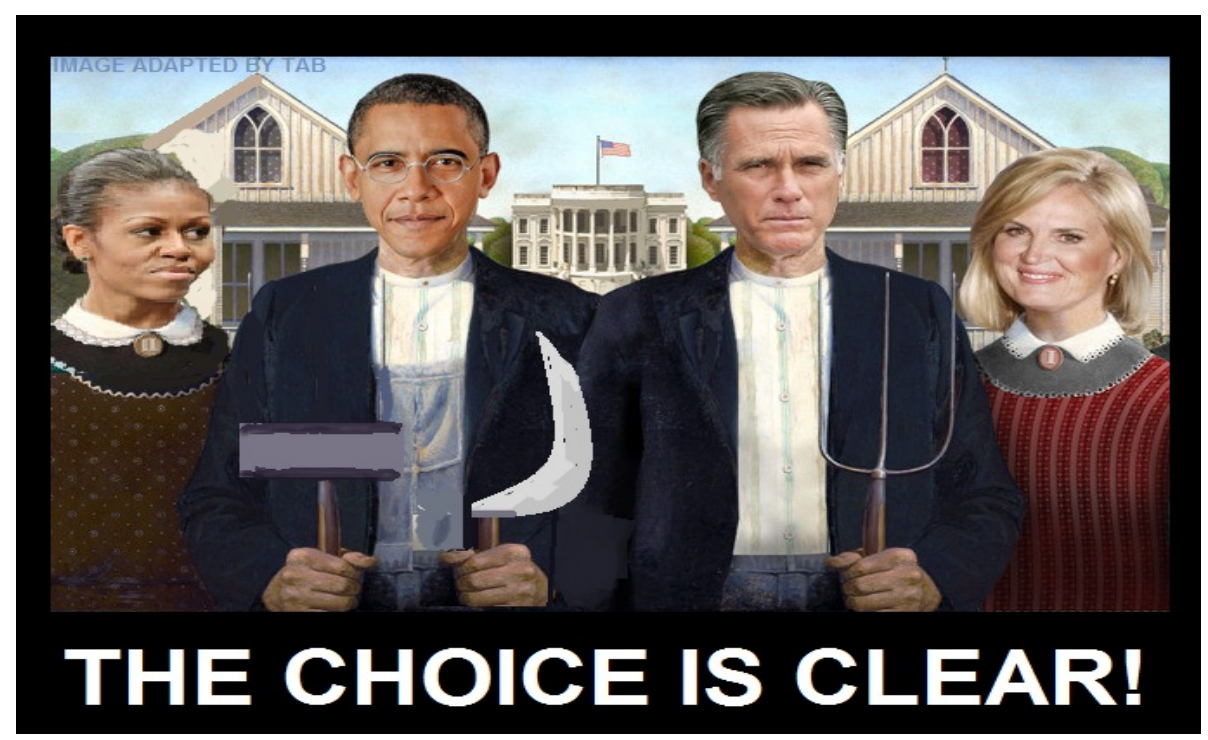

Ecofanía no. 3b: ¡La elección está clara! (the choice is clear!)

Transcurrido su primer mandato Barack Obama se presentó en 2012 a la reelección para un segundo en el que su rival republicano fue Mitt 
Romney ex gobernador y acaudalado hombre de negocios. Dos modelos de familia luchan por la Casa Blanca situada en el centro de la imagen como un objeto en disputa.

Una pareja blanca republicana conservadora, Romney y su esposa Ann Romney, (de soltera Davies), configurando el matrimonio mormón perfecto. Situados de manera inversa a la del cuadro de Grant Wood para facilitar la comprensión de que quienes se enfrentan por la presidencia son los dos hombres. Los esposos se hallan ante una casa en la que la ventana central ojival con parteluz tiene cortinas rojas (color del partido republicano). El mormonismo es un estilo de vida caracterizado por una serie de creencias tanto religiosas como políticas: la identidad religiosa marca sus vidas, se trata de una religión nacida en EE.UU. por ello quieren encarnar las virtudes consideradas auténticamente estadounidenses: la confianza en sí mismos, el individualismo y las altas expectativas de moralidad.

El mormón no consume tabaco, alcohol ni café y da prioridad a la familia. Romney ha estado casado con la misma mujer muchos años, desde 1969, y tienen cinco hijos y diez nietos. La esposa mormona tiene asignado un papel diferente que el del varón, siendo uno de sus roles específicos el cuidado de sus hijos esa es una de las principales razones por las que Ann apenas aparece en foros públicos. El varón mormón ha de ser misionero, puesto que extender la palabra de Dios es una materia muy seria dentro del mormonismo. Por esta razón, Romney estuvo realizando su labor como misionero durante más de dos años en Francia. Los mormones son hábiles en los negocios, y Romney es un ejecutivo de gran éxito en el sector privado, habiendo ocupado multitud de cargos de gran responsabilidad. Desde un punto de vista político, ellos consideran que la Constitución estadounidense es un documento divinamente inspirado y que tiene ciertas equivalencias con la Biblia y con el libro del mormón. Se oponen al divorcio $y$ al sexo fuera del matrimonio; son antiabortistas (aunque contemplan ciertas excepciones); han sido tradicionalmente racistas, especialmente contra los negros, si bien en 1978 su iglesia recibió una revelación cambiando esta enseñanza.

Los considerados consortes comunistas son una pareja negra demócrata y liberal conformada por Barack Obama (con la hoz y el martillo) y su esposa Michael, colocados ante la casa en la posición original de American Gothic, pero en este caso las cortinas de la ventana central aparecen de color azul (color del partido demócrata). Constituyen una pareja de compañeros ${ }^{20}$ que ha roto varios de los clichés acerca de lo que

20 Michelle ha afirmado en los medios que antes que nada es madre de Malia y de Sasha pero también es esposa, abogada y funcionaria pública. Desde su juventud ha estado involucrada 
es un matrimonio presidencial: son negros, son inteligentes, son carismáticos y Michelle es la Primera Dama con la actuación política real más grande de la historia de los EE.UU., lo que significa representar una imagen muy positiva ante la sociedad estadounidense $y$, muy especialmente, la de ser un referente a imitar para las mujeres negras. En su función de primera dama, Michael ha utilizado su influencia para promover la salud infantil y también fue ella quien estableció el programa "Let's Move" (¡A moverse!) una iniciativa diseñada para acabar con la obesidad infantil que en las últimas tres décadas se había triplicado en EE.UU., que afecta de manera especial a los niños latinos. Trabaja también en apoyo de las familias con parientes en las fuerzas armadas y en la asistencia a las mujeres que tratan de equilibrar trabajo y familia. El presidente es considerado comunista por la derecha conservadora, por su relación con círculos de izquierda durante su adolescencia y, especialmente, por su reforma del sistema de salud, que obliga a todos los estadounidenses a tener un seguro médico. Los conservadores más extremistas están dispuestos a frenar esta iniciativa a cualquier precio. Expulsar al comunista Barack Obama de la Casa Blanca fue la consigna generalizada de la campaña republicana en la que se afirmaba rotundamente que el país nunca se recuperaría si el presidente obtenía un segundo mandato.

\section{CONCLUSIÓN}

La obra de arte como campo de estímulos diversos se presta, en multitud de ocasiones, a ser reconvertida a causa de su ambigüedad consustancial en réplicas o knockoffs producidas por 'receptores activos' que con sus propias interpretaciones crean una serie insólita de metarepresentaciones polarizadas como una 'plástica cotidiana de la disensión política'. Consideramos que cualquier elemento plástico de una cultura está en constante proceso de creación y renegociación por parte de sus interpretantes, quienes, con sus aportaciones 'culturales', lo irán enriqueciendo continuamente mediante un proceso que nosotros hemos denominado 'ecoicidad' o producción de nuevos ecos comunicativos epidemiológicos de una matriz original.

La Teoría de la Relevancia aplicada al arte y a sus ecos se asienta sobre cuatro pilares: a) cada obra posee una variedad de posibles interpretaciones; b) el receptor no recibe todas esas interpretaciones posibles de la misma forma, sino que algunas requieren más esfuerzo de

en actividades sociales de ayuda a la comunidad mediante el estímulo y preparación de personas para el voluntariado. 
procesamiento que otras; c) cada receptor en particular está dotado de un único criterio general para evaluar las interpretaciones; d) este criterio es lo suficientemente poderoso para excluir todas las interpretaciones excepto una que es la que finalmente se acepta (meta-representación individual). El contradiscurso político-electoral sobre Barack Obama fundamentado en obras de arte puede ser abordado desde la Teoría de la Relevancia como un caso práctico (praxis icónico-verbal de publicidad activa) basada en el arte que ayude a complementar los abundantes estudios teóricos, en muchos casos, saturados de metalenguaje.

REFERENCIAS BIBLIOGRÁFICAS

Alvarez De Prada, G., Didáctica del discurso icónico-verbal: las artes plásticas como pretexto publicitario. (Tesis Doctoral). Universidad de Córdoba. Biblioteca General: FCE-2003-ALV (tres tomos), 2003.

BARTHES, Roland, La muerte del autor en el susurro del lenguaje. Madrid: Paidós, 1995.

CAlABRese, O., El lenguaje del arte. Madrid: Paidós Ibérica, 1997.

CULLER, Jonathan, Literary theory. A very short introduction. Oxford: Oxford University Press, 1997.

Eco, Umberto, La estructura ausente. Introducción a la semiótica. Barcelona: Lumen, 1978.

—, Apocalípticos e Integrados. Barcelona: Tusquets, 1995 (1968).

Lector in fabula, Barcelona: Lumen, 1993.

GuIJARRO MORALES, J.L., "Encuadre del fenómeno del arte en el nuevo paradigma científico del cognitivismo". En Cuadernos del Minotauro, $\mathrm{n}^{\circ} .2,2005$, pp. 17-48.

GuTT, Ernest-A., Translation and Relevance: cognition and context. Manchester: St Jerome Publishing; 2nd edition, 2000 (1991).

JoRgensen,J.; Miller, G.,SPERBER,D., "Test of the mention theory of irony". En: Journal of Experimental Psychology: (General 113), 1984, pp. 112-120.

LÓPEZ FolgADO, V., "Traducción y relevancia: ¿qué quiere decir 'semejanza interpretativa' en traducción". En Perdu Honeyman, N. (ed.) Cambio de dimensiones en traducción y comunicación. Almería: Editorial Universidad de Almería, 2010, pp. 47-71.

MANGUEL, Alberto, En el bosque del espejo. Ensayos sobre las palabras y el mundo. Madrid: Alianza, 2001.

Moles, Abraham A., El kitsch. El arte de la felicidad. Trad.: Josefina Ludmer. $1^{a}$ ed. Buenos Aires: Paidós, 1971. (Barcelona, 1990).

PILKIngton, Adrian, Poetic Effects. Amsterdam: John Benjamins, 2000. 
SPERBER, D. \& WILSON, D., Relevance: communication and cognition, Oxford: Blackwell, 1995 (1986).

Sperber, D. (ed.), Metarepresentations. A multidisciplinary debate. Oxford and New York: Oxford University Press, 2000.

_- Explaining culture: a naturalistic approach. Oxford, Blackwell, 1996.

TANAKA, Keiko, Advertising Language. London: Routledge, 1994.

WILSON D., "Metarepresentation in linguistic communication". En D. Sperber (ed.): Metarepresentations. A multidisciplinary perspective. Oxford: Oxford University Press, 2000, pp. 117-137.

WILSON, D. \& SPERBER, D., "Relevance Theory". In Horn, L.R. \& Ward, G. (eds.) The Handbook of Pragmatics. Oxford: Blackwell, 2004, pp. 607632.

Yus RAmOS, F., La interpretación y la imagen de masas. Alicante: Diputación de Alicante, Instituto Juan Gil-Albert, 1997.

_-, Ciberpragmática. El uso del lenguaje en Internet. Barcelona: Ariel, 2001

YUSTE FRÍAS, J., "Leer e interpretar la imagen para traducir", Trabalhos em Linguística Aplicada, vol. 50, n. ${ }^{\circ}$ 2, 2011, pp. 257-280.

ZABALBEASCOA TERRAN, P., "Aplicaciones de la traducción a la enseñanza de las lenguas extranjeras". En: Sintagma 2, 1990, pp. 75-86.

ZUnZUneGuI, S., Pensar la imagen. Madrid: Cátedra, 2007. 